\title{
Perborate Oxidation of Substituted 5-Oxoacids in Aqueous Acetic Acid Medium: A Kinetic and Mechanistic Study
}

\author{
S. Shree Devi, ${ }^{1,2}$ B. Muthukumaran, ${ }^{3}$ and P. Krishnamoorthy ${ }^{4}$ \\ ${ }^{1}$ Research and Development Centre, Bharathiar University, Coimbatore 641 046, India \\ ${ }^{2}$ Department of Chemistry, Arignar Anna Government Arts College, Cheyyar 604 407, India \\ ${ }^{3}$ Department of Chemistry, Presidency College, Chennai 600005, India \\ ${ }^{4}$ Department of Chemistry, Dr. Ambedkar Government Arts College, Chennai 600 039, India
}

Correspondence should be addressed to P. Krishnamoorthy; krishthi@hotmail.co.uk

Received 22 November 2013; Accepted 5 January 2014; Published 4 February 2014

Academic Editors: M. Sikorski, D. Strout, and D. A. Wild

Copyright (C) 2014 S. Shree Devi et al. This is an open access article distributed under the Creative Commons Attribution License, which permits unrestricted use, distribution, and reproduction in any medium, provided the original work is properly cited.

\begin{abstract}
Kinetics and mechanism of oxidation of substituted 5-oxoacids by sodium perborate in aqueous acetic acid medium have been studied. The reaction exhibits first order both in [perborate] and [5-oxoacid] and second order in $\left[\mathrm{H}^{+}\right]$. Variation in ionic strength has no effect on the reaction rate, while the reaction rates are enhanced on lowering the dielectric constant of the reaction medium. Electron releasing substituents in the aromatic ring accelerate the reaction rate and electron withdrawing substituents retard the reaction. The order of reactivity among the studied 5-oxoacids is $p$-methoxy $\gg p$-methyl $>p$-phenyl $>-\mathrm{H}>p$-chloro $>p$-bromo $>m$-nitro. The oxidation is faster than $\mathrm{H}_{2} \mathrm{O}_{2}$ oxidation. The formation of $\mathrm{H}_{2} \mathrm{BO}_{3}{ }^{+}$is the reactive species of perborate in the acid medium. Activation parameters have been evaluated using Arrhenius and Eyring's plots. A mechanism consistent with the observed kinetic data has been proposed and discussed. Based on the mechanism a suitable rate law is derived.
\end{abstract}

\section{Introduction}

Sodium perborate $\left(\mathrm{NaBO}_{3} \cdot 4 \mathrm{H}_{2} \mathrm{O}\right)$ is a nontoxic cheap large scale industrial chemical primarily used as a source of "active oxygen" in detergents and as a mild antiseptic. This active oxygen has the oxidising properties of hydrogen peroxide. PMR spectral analysis [1] and X-ray diffraction studies [2] conclude that perborate is a true peroxy salt with water of crystallisation. Perborate is a heterocycle and is in a dimeric tetrahedral configuration with dihedral angle of $64^{\circ}$ and anionic formula: $\mathrm{B}_{2}\left(\mathrm{O}_{2}\right)_{2}(\mathrm{OH})_{4}{ }^{2-}$ [3]. Oxidative study suggests perborate as not peroxoborate but borate peroxyhydrate. Hydrogen peroxide acquires stronger electrophilicity by the coordination with borate [4]. It is an effective reagent in organic synthesis and acetic acid is the solvent of choice [57]. Perborate in aqueous solution yields hydrogen peroxide and the kinetic studies in aqueous and partly aqueous acidic media confirm that perborate oxidation is hydrogen peroxide oxidation [8-10]. This stable and easily handled crystalline substance oxidizes organic sulphides [11-13], anilines [14], and indole [15].

5-Oxoacid is an attractive substrate in terms of its enolization. In strong acid medium the substrate undergoes enolization. The reactive species of the substrate has been reported in the literature to be the enol form $[16,17]$.

In recent years, studies of the oxidation of various organic compounds by perborate have attracted considerable attention. A thorough literature survey reveals that relatively little work on the oxidation of oxoacid has been reported so far [18-21]. Although the perborate oxidation of organic compounds has been studied, there seems to be no report on a systematic kinetic study of the oxidation of 5-oxoacids by perborate and we report here for the first time the kinetics and mechanism of perborate oxidation of substituted and unsubstituted 5-oxoacids. The various unsubstituted and substituted 5-oxoacids (S1-S7) employed in the present study are listed in Figure 1. 


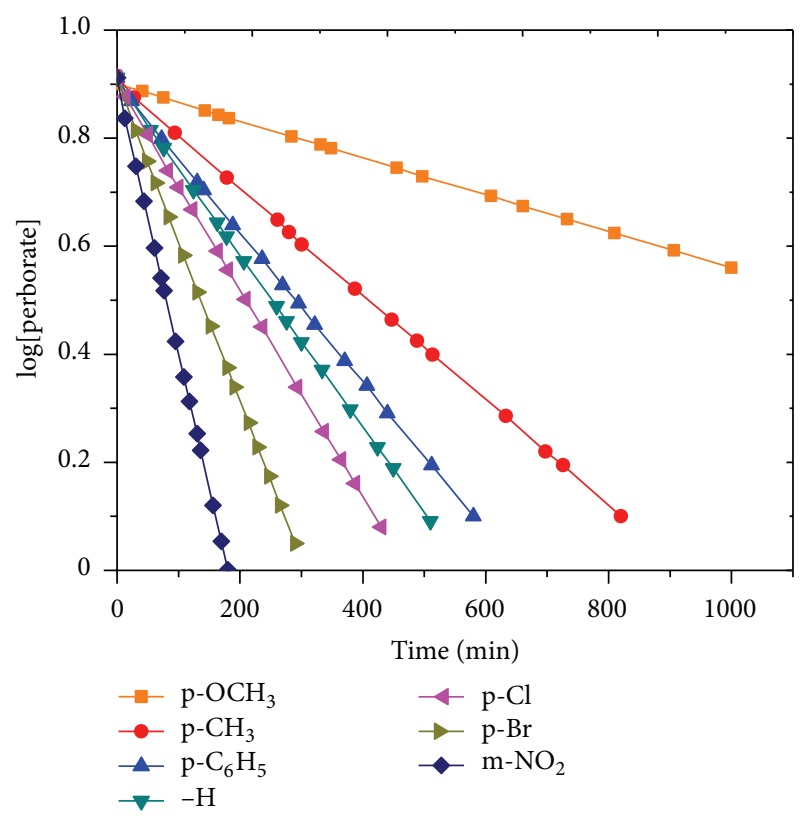

FIgURE 1: S1: unsubstituted, S2: $4^{\prime}$-methoxy, S3: $4^{\prime}$-methyl, S4: $4^{\prime}$ phenyl, S5: $4^{\prime}$-chloro, S6: $4^{\prime}$-bromo, and S7: $3^{\prime}$-nitro.

\section{Experimental}

2.1. Materials. Sodium perborate, $\mathrm{NaBO}_{3} \cdot 4 \mathrm{H}_{2} \mathrm{O}$ (Riedel), was used as received. Acetic acid (BDH) was refluxed for $6 \mathrm{~h}$ over chromium (VI) oxide and distilled through a column. Aqueous solutions of perborate were prepared as and when required and standardized iodometrically. Sodium metaborate and perchloric acid were prepared in double distilled water. Double distilled water (conductivity $<10 \mu \mathrm{S} \cdot \mathrm{cm}^{-1}$ ) has been employed in all kinetic runs. All the chemicals used were $99.8 \%$ pure. The parent 5-oxoacid, namely, 5-oxo-5-phenylpentanoic acid (S1), and the phenyl substituted 5-oxoacids (S2-S7) were prepared by FriedelCrafts acylation of the substituted benzene with glutaric anhydride [22-26]. All the 5-oxoacids were crystallized twice from water and their purity was checked by their melting points and UV, IR, and NMR spectra. All other chemicals were of analytical grade.

All absorption measurements were made with Shimadzu UV-visible spectrophotometer (MPS-5000) equipped with a temperature controller. Regression analysis of experimental data yielded the regression coefficient $(r)$ and standard deviation $(s)$.

2.2. Kinetic Measurements. The reaction mixture, containing 5-oxoacid and sulphuric acid solutions, was thermally equilibrated and the reaction was initiated by the addition of temperature-equilibrated perborate solution of requisite concentration. The oxidation kinetics was followed in aqueous acetic acid at constant temperature by measuring the concentration of benzoic acid formed iodometrically under pseudo-first order conditions by keeping the substrate in excess over the oxidant. The pseudo-first-order rate constant $\left(k^{\prime}\right)$ was calculated from the slope of the linear plot of ln [perborate] versus time by the method of least squares. The error quoted in $k^{\prime}$ is the $95 \%$ confidence limit of the Student's $t$-test. The progress of the oxidation was followed by iodometric determination of the oxidant. Freshly prepared solutions of oxoacids in purified acetic acid were used to avoid any possible side reactions.

2.3. Reaction Stoichiometry and Product Analysis. The stoichiometry of the reaction was determined by equilibrating reaction mixture of various [perborate]/[5-oxoacid] ratios at $313 \mathrm{~K}$ for $12 \mathrm{~h}$, keeping all other reagents constant. Estimation of unconsumed perborate (iodometrically) revealed that one mole of 5-oxoacid consumed one mole of perborate:

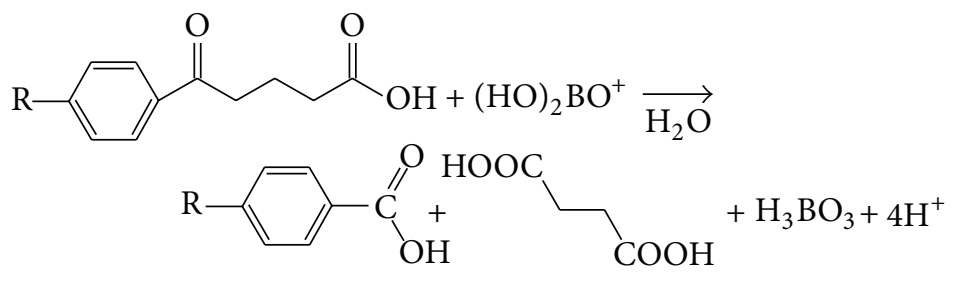

The products were extracted with ether, dried, and analyzed. Benzoic acid was identified by its melting point $\left(121^{\circ} \mathrm{C}\right)$. Then it has been estimated quantitatively using UV-Vis spectrophotometry with a standard curve at $\lambda_{\max }=235 \mathrm{~nm}$. Succinic acid was identified by its melting point $\left(185^{\circ} \mathrm{C}\right)$ and also tested with its characteristic spot test [27]. Identification of the products, namely, benzoic and succinic acids, was also made by comparing the $R_{f}$ values of the authentic samples. Boric acid was identified by adding an alkaline solution of benzoin, resulting in the formation of a yellow-green fluorescent complex.

\section{Results and Discussion}

At fixed concentrations of acid and substrate, the decrease in the concentration of perborate is followed first order kinetics. The first order rate constants $\left(k_{1}\right)$ were calculated from the linear plots $(r \geq 0.98, s \leq 0.03)$ of log [perborate] against time. Such plots are linear for more than three half-lives of the reaction (Figure 2). The $k_{1}$ value was independent of initial [perborate] for all the studied substrates.

The reactions of all the studied 5-oxoacids are first order in the [substrate] (Table 1 ) and in $\left[\mathrm{H}^{+}\right]^{2}$ in the range of 
TABLE 1: Effect of varying [substrate] on the rate of perborate oxidation of 5-oxoacids at $313 \pm 0.1 \mathrm{~K} .\left\{[\right.$ Perborate $]=0.001 \mathrm{~mol} \mathrm{dm}^{-3} ;\left[\mathrm{H}_{2} \mathrm{SO}_{4}\right]=$

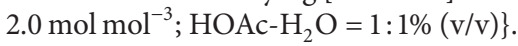

\begin{tabular}{|c|c|c|c|c|c|c|c|}
\hline \multirow{2}{*}{ [5-oxo acid] $\left(\mathrm{mol} \mathrm{dm}^{-3}\right)$} & \multicolumn{7}{|c|}{$10^{5} \times k_{\mathrm{obs}}\left(\mathrm{s}^{-1}\right)^{\mathrm{a}}$} \\
\hline & $p-\mathrm{OCH}_{3}$ & $p-\mathrm{CH}_{3}$ & $p-\mathrm{C}_{6} \mathrm{H}_{5}$ & $-\mathrm{H}$ & $p-\mathrm{Cl}$ & $p-\mathrm{Br}$ & $m-\mathrm{NO}_{2}$ \\
\hline 0.005 & 95.91 & 13.44 & 9.43 & 6.36 & 2.14 & 1.77 & 0.77 \\
\hline 0.01 & 191.9 & 26.85 & 21.67 & 12.78 & 4.25 & 2.15 & 1.52 \\
\hline 0.015 & 287.9 & 40.33 & 29.98 & 19.20 & 6.40 & 4.43 & 2.34 \\
\hline 0.02 & 383.7 & 53.71 & 36.71 & 25.59 & 8.51 & 5.74 & 3.05 \\
\hline 0.03 & 575.8 & 80.59 & 60.76 & 38.14 & 12.78 & 8.92 & 4.56 \\
\hline 0.04 & 767.7 & 107.5 & 124.91 & 51.13 & 17.15 & 12.53 & 6.05 \\
\hline 0.06 & 1152 & 161.3 & 142.24 & 76.75 & 25.59 & 17.53 & 9.10 \\
\hline
\end{tabular}

${ }^{\mathrm{a}}$ Mean of duplicate experiments.

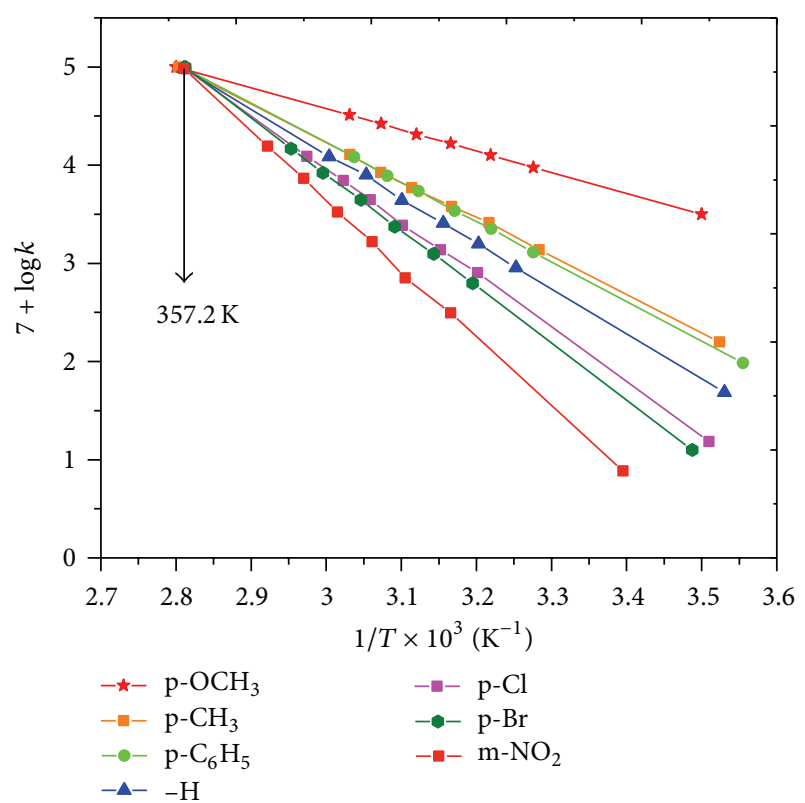

FIgURE 2: Typical first order plots in the perborate oxidation of 5oxoacids.

$0.5-4.0 \mathrm{~mol} \mathrm{dm}^{-3}$ sulphuric acid (Table 2). From the ZuckerHammett plots of $\log k$ versus $-\mathrm{H}_{\mathrm{o}}$, the slopes obtained were in the range of 1.0-1.2, indicating the noninvolvement of water molecule in the rate determining step. The $\mathrm{H}_{\mathrm{o}}$ values were taken from Long and Paul [28] assuming that the $\mathrm{H}_{\mathrm{o}}$ values do not change much in a media containing acetic acid up to $50 \%$.

The effect of dielectric constant $(D)$ on the rate of reaction was studied by varying acetic acid-water content in the reaction mixture. Acetic acid does not react with the oxidants [29], yet the rate of the reaction is enhanced by increasing acetic acid content of the medium (Table 3). Also, $\log k$ against $1 / D$ is found linear, suggesting a positive ion-dipole type of interaction [30] in the rate determining step.

There was no induced polymerization of acrylonitrile monomer, ruling out the possibility of free radical formation during the course of the reaction.

In the temperature range of $298-323 \mathrm{~K}$ in $2.0 \mathrm{~mol} \mathrm{dm}^{-3}$ sulphuric acid and acetic acid-water medium (50\% v/v)
(Figure 3), the activation energy $\left(E_{a}\right)$ and related thermodynamic parameters $\left(\Delta H^{\#}, \Delta G^{\#}\right.$, and $\left.\Delta S^{\#}\right)$ were evaluated. The plot between $\Delta H^{\#}$ and $\Delta S^{\#}$ is linear (Figure $4, r \geq 0.98, s \leq$ 0.028 ) and the isokinetic temperature $(\beta)$ obtained is $357 \mathrm{~K}$. The isokinetic relationship in the present study implies that all the 5-oxoacids undergo oxidation by the same mechanism [31].

The effect of substituents on the rate of oxidation was studied using different phenyl substituted 5-oxoacids $\left(\mathrm{ArCOCH}_{2} \mathrm{CH}_{2} \mathrm{CH}_{2} \mathrm{COOH}\right.$, where $\mathrm{Ar}=4^{\prime}$-methoxy, $4^{\prime}$ methyl, $4^{\prime}$-phenyl, $4^{\prime}$-chloro, $4^{\prime}$-bromo, $3^{\prime}$-nitro substituted phenyl) at different temperatures. In all these cases, the reaction orders are the same, namely, first order with respect to [oxidant] and [substrate] and second order with respect to [acid]. Electron releasing substituents in the phenyl ring enhance the rate of oxidation and electron withdrawing substituents decrease it (Table 4 ). The order of reactivity among the studied 5-oxoacids is $p$-methoxy $\gg p$-methyl $>$ $p$-phenyl $>-\mathrm{H}>p$-chloro $>p$-bromo $>m$-nitrophenyl substituted 5-oxoacids. The Hammett plots of $\log k$ versus $\sigma$ (substituent constant) are smooth curves and concave downward, at all the studied temperatures. However, the Hammett plots are linear with good correlation coefficient at four different temperatures when exalted substituent constant $\left(\right.$ Brown's $\sigma^{+}$) values are used (Figure 5). The reaction constant $\left(\rho^{+}\right)$is negative and decreases (in magnitude) from -1.65 to -1.32 with increasing temperature from $303 \mathrm{~K}$ to $323 \mathrm{~K}$. The Hammett lines intersect at a point correspondent to a $\sigma_{\text {iso }}^{+}$ value of -1.42 and a $k_{\text {iso }}$ value of $13.18 \times 10^{-3} \mathrm{~s}^{-1}$ (Figure 5). An oxoacid with a substituent having this $\sigma^{+}$value $(-1.42)$ will be oxidized by perborate at the same rate at all temperatures. Such insensitivity of the reaction rate to temperature is a pointer to the existence of an isokinetic phenomenon.

A reaction series which exhibits a common point of intersection in the Hammett plot (Figure 5) is expected to have a common point of intersection in the Arrhenius plot as well [32]. From the plots of $\Delta H^{\#}$ against $\Delta S^{\#}$ and $\rho$ against $1 / T$, the $T_{\text {iso }}$ value is found to be $359 \mathrm{~K}$, which is in good agreement with the value obtained from the slope of Exner's plot.

3.1. Mechanism. In aqueous acetic acid the possible oxidizing species of perborate are perborate anion, perboric acid, peracetic acid, and $\mathrm{H}_{2} \mathrm{O}_{2}$. Even though isolation of free 
TABLE 2: Effect of varying $\left[\mathrm{H}_{2} \mathrm{SO}_{4}\right]$ on the rate of perborate oxidation of 5-oxoacids at $313 \pm 0.1 \mathrm{~K}$. $\left\{[\right.$ Substrate $]=0.01 \mathrm{~mol} \mathrm{dm}^{-3}$; [perborate $]=$ $\left.0.001 \mathrm{~mol} \mathrm{dm}^{-3} ; \mathrm{HOAc}-\mathrm{H}_{2} \mathrm{O}=1: 1 \%(\mathrm{v} / \mathrm{v})\right\}$.

\begin{tabular}{|c|c|c|c|c|c|c|c|c|}
\hline \multirow{2}{*}[\mathrm{H}_{2}\mathrm{SO}_{4}]{$\left(\mathrm{mol} \mathrm{dm}^{-3}\right)$} & \multirow{2}{*}{$-\mathrm{H}_{\mathrm{o}}$} & \multicolumn{7}{|c|}{$10^{5} \times k\left(\mathrm{~s}^{-1}\right)^{\mathrm{a}}$} \\
\hline & & $p-\mathrm{OCH}_{3}$ & $p-\mathrm{CH}_{3}$ & $p-\mathrm{C}_{6} \mathrm{H}_{5}$ & $-\mathrm{H}$ & $p-\mathrm{Cl}$ & $p-\mathrm{Br}$ & $m-\mathrm{NO}_{2}$ \\
\hline 0.51 & -0.13 & 11.89 & 2.31 & 1.87 & 1.58 & - & - & - \\
\hline 0.75 & 0.07 & 29.93 & 4.38 & 3.28 & 2.88 & - & - & - \\
\hline 1.01 & 0.26 & 47.98 & 7.68 & 5.19 & 4.52 & 1.27 & 1.21 & 1.18 \\
\hline 1.49 & 0.56 & 95.96 & 15.98 & 12.67 & 8.84 & 2.32 & 1.98 & 1.26 \\
\hline 2.01 & 0.84 & 191.9 & 26.87 & 19.28 & 12.78 & 4.26 & 3.09 & 1.52 \\
\hline 2.49 & 1.12 & 287.9 & 47.98 & 38.69 & 25.59 & 7.19 & 5.16 & 2.57 \\
\hline 3.00 & 1.38 & 479.8 & 134.3 & 79.81 & 34.85 & 12.79 & 7.28 & 3.97 \\
\hline 4.01 & 1.85 & 1151 & 287.8 & 140.63 & 57.58 & 25.58 & 16.89 & 7.69 \\
\hline$S^{\mathrm{b}}$ & & 2.01 & 2.01 & 2.0 & 2.00 & 2.01 & 2.0 & 2.00 \\
\hline$n^{\mathrm{c}}$ & & 1.3 & 1.0 & 1.0 & 1.0 & 1.1 & 1.1 & 1.0 \\
\hline
\end{tabular}

${ }^{\mathrm{a}}$ Mean of duplicate experiments; ${ }^{\mathrm{b}}$ slopes of $\log k$ versus $\log \left[\mathrm{H}_{2} \mathrm{SO}_{4}\right] ;{ }^{\mathrm{c}}$ slopes of the Zucker-Hammett plots.

TABLE 3: Effect of varying solvent composition on the rate of perborate oxidation of 5 -oxoacids at $313 \pm 0.1 \mathrm{~K}$. \{[Substrate $]=0.01 \mathrm{~mol} \mathrm{dm}^{-3}$; [perborate] $\left.=0.001 \mathrm{~mol} \mathrm{dm}^{-3} ;\left[\mathrm{H}_{2} \mathrm{SO}_{4}\right]=2.0 \mathrm{~mol} \mathrm{~mol}^{-3}\right\}$.

\begin{tabular}{|c|c|c|c|c|c|c|c|}
\hline \multirow{2}{*}{$\mathrm{ACOH}-\mathrm{H}_{2} \mathrm{O}(\mathrm{v} / \mathrm{v}, \%)$} & \multicolumn{7}{|c|}{$10^{5} \times k\left(\mathrm{~s}^{-1}\right)^{\mathrm{b}}$} \\
\hline & $p-\mathrm{OCH}_{3}$ & $p-\mathrm{CH}_{3}$ & $p-\mathrm{C}_{6} \mathrm{H}_{5}$ & $-\mathrm{H}$ & $p-\mathrm{Cl}$ & $p-\mathrm{Br}$ & $m-\mathrm{NO}_{2}$ \\
\hline $30: 70$ (53.18) & 63.8 & 9.50 & 8.67 & 7.60 & 2.38 & 1.97 & 1.18 \\
\hline $40: 60(46.48)$ & 115.2 & 13.10 & 11.86 & 9.60 & 3.10 & 2.12 & 1.29 \\
\hline $50: 50(39.78)$ & 191.8 & 26.87 & 18.73 & 12.80 & 4.27 & 3.62 & 1.50 \\
\hline $60: 40(33.08)$ & 586 & 44.70 & 31.01 & 15.90 & 7.20 & 4.89 & 1.75 \\
\hline $70: 30(26.38)$ & 1751 & 162.9 & 71.23 & 38.30 & 12.80 & 7.61 & 2.69 \\
\hline
\end{tabular}

${ }^{\mathrm{a}}$ Values of dielectric constant of the media are given in parentheses; ${ }^{\mathrm{b}}$ mean of duplicate experiments.

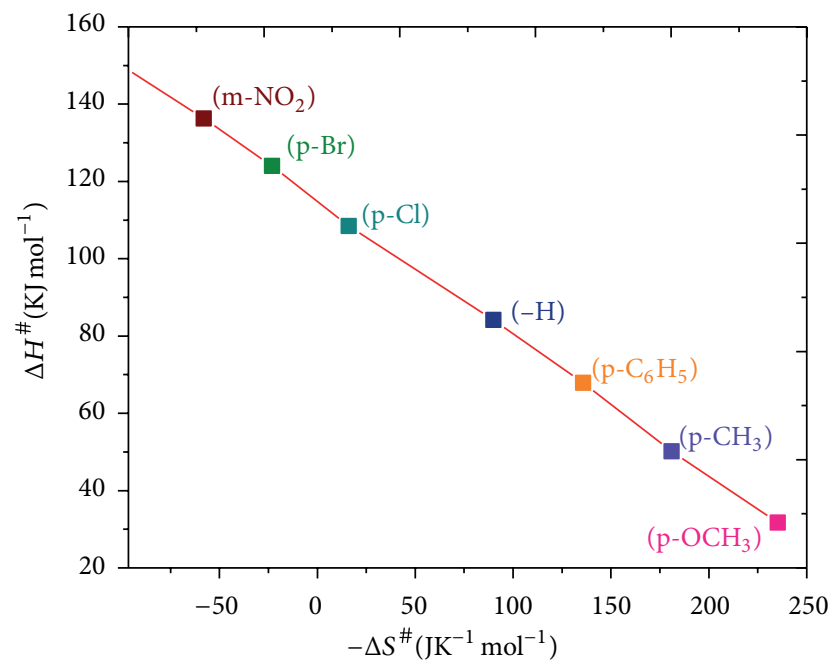

FIGURE 3: Arrhenius plots of $\log k$ against $1 / T$ showing the isokinetic temperature.

perboric acid has been proved exceedingly difficult, it has demonstrable existence in solution [33]. Perborate is reported to exist in a dimeric tetrahedral configuration with the anionic formula: $\mathrm{B}_{2}\left(\mathrm{O}_{2}\right)_{2}(\mathrm{OH})_{4}{ }^{2-}$. The oxidation has been carried out in aqueous acetic acid, and from the ionization constant of perboric acid, reported as $(0.6-1.6) \times 10^{-8}$, it
TABLE 4: Effect of substituent on the rate of oxidation of 5-oxoacids by perborate at $313 \pm 0.1 \mathrm{~K}$. \{[Substrate $]=0.01 \mathrm{~mol} \mathrm{dm}^{-3}$; [perborate] $=0.001 \mathrm{~mol} \mathrm{dm}^{-3} ;\left[\mathrm{H}_{2} \mathrm{SO}_{4}\right]=2.0 \mathrm{~mol} \mathrm{~mol}{ }^{-3} ; \mathrm{HOAC}^{-} \mathrm{H}_{2} \mathrm{O}=1: 1 \%$ $\mathrm{v} / \mathrm{v}\}$.

\begin{tabular}{lcccc}
\hline Substituent & $\sigma$ & $\sigma^{+}$ & $10^{5} \times k\left(\mathrm{~s}^{-1}\right)$ & $5+\log k$ \\
\hline$p-\mathrm{OCH}_{3}$ & -0.27 & -0.78 & 191.8 & 2.2829 \\
$p-\mathrm{CH}_{3}$ & -0.17 & -0.31 & 26.9 & 1.4293 \\
p-C6H5 & -0.11 & -0.22 & 18.8 & 1.2623 \\
$-\mathrm{H}$ & 0.00 & 0.00 & 12.8 & 1.1070 \\
$p-\mathrm{Cl}$ & 0.23 & 0.11 & 4.3 & 0.6299 \\
$p-\mathrm{Br}$ & 0.43 & 0.38 & 2.7 & 0.3470 \\
$m-\mathrm{NO}_{2}$ & 0.71 & 0.67 & 1.5 & 0.1802 \\
\hline
\end{tabular}

may be concluded that perborate exists mainly as perboric acid in aqueous acetic acid, at very low $\mathrm{pH}$ maintained with sulphuric acid and hence is unlikely to be the oxidant. The rate of perborate oxidation in aqueous acetic acid compares with that in aqueous ethanol, and hence the oxidation is not through peracetic acid. $\mathrm{H}_{2} \mathrm{O}_{2}$ is less likely to be the oxidant as the rate of $\mathrm{H}_{2} \mathrm{O}_{2}$ oxidation is about one-fifth of that of perborate oxidation. The enhancement of reaction rate with an increase in the amount of acetic acid and linear plots of $\log k$ versus $1 / D$ with positive slopes indicate an interaction between a positive ion and a dipole molecule in the slow step. This supports the postulation of $\mathrm{H}_{2} \mathrm{BO}_{3}{ }^{+}$as the reactive 


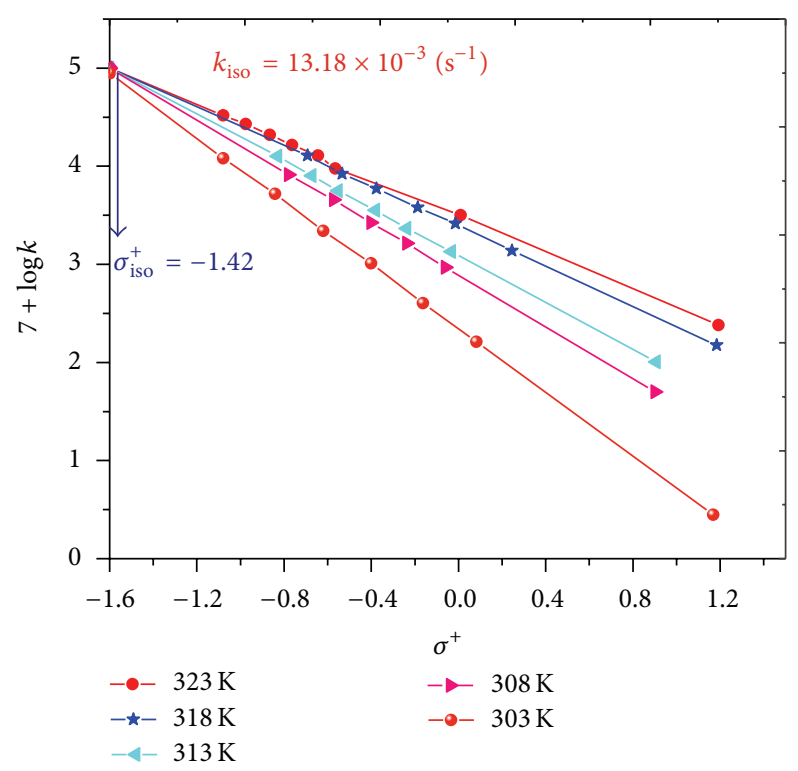

FIGURE 4: Plot of $\Delta H^{\#}$ against $-\Delta S^{\#}$ showing the isokinetic relationship.<smiles>O=C(O)CCCC(=O)c1ccccc1</smiles>

Figure 5: Hammett plots of $\log k$ against $\sigma_{+}$at different temperatures. species of perborate in the acid medium. The rate acceleration with an increase in [acid] and second order dependence of rate on [acid] in the range studied also confirm that $\mathrm{H}_{2} \mathrm{BO}_{3}{ }^{+}$ is the reactive species of perborate taking part in the oxidation of 5-oxoacids.

The oxoacid is a weak acid $\left(p K_{a}=5.77\right.$ at $40^{\circ} \mathrm{C}$ in aqueous solution) [34], and the undissociated form of the substrate can be taken as the only form in acidic media. In acid solutions, 5-oxoacid undergoes keto enol tautomerism (2):

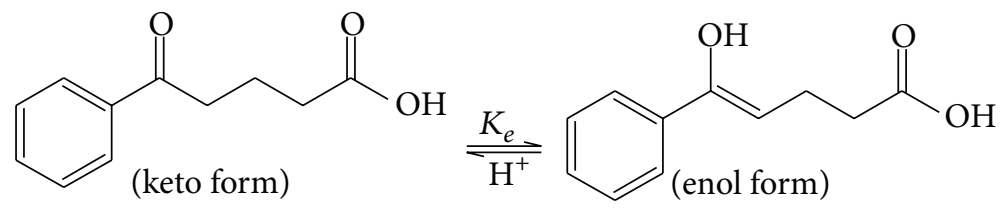

In oxidation reactions, the keto group of the substrate can react either directly or through the enol form. Oxidation rates faster than the rates of enolization have been observed with ceric ion [35], manganic ion [36], cobaltic vanadate ions [37], mercuric perchlorate [38], and alkaline diperiodate argenate(III) [39] as oxidants, indicating that the keto group of the substrate reacts directly. All of these oxidants undergo one-electron reduction, and the reactions proceeded via a free radical mechanism [35-39].

The rates of oxidation and enolization were found to be equal in the oxidation reactions by manganic pyrophosphate [40], thallium triacetate [41], and by diperiodatonickelate (IV) [42]. These reactions were zero order in [oxidant], indicating the enol formation as the rate determining step.
In the present study, the rate of enolization (measured by the bromination method [43]) is greater than the rate of oxidation by a factor of $\sim 13-15$ and the enolization step can be visualized as proceeding via the enol form of the keto group of 5-oxoacid. Hence, the step involving enol formation can be assumed to be a fast step and thus is not the rate determining step of the reaction. The most plausible mechanism therefore seems to be shown in Scheme 1. The proposed mechanism is also in accordance with the observed stoichiometry. The rate equation in consonance with the mechanism proposed is as given in the following equation:

$$
\left.\frac{-d[\text { perborate }]}{d t}=K_{p} K_{e} k\left[\mathrm{H}^{+}\right]^{2} \text { [5-oxoacid] [perborate }\right] \text {. }
$$




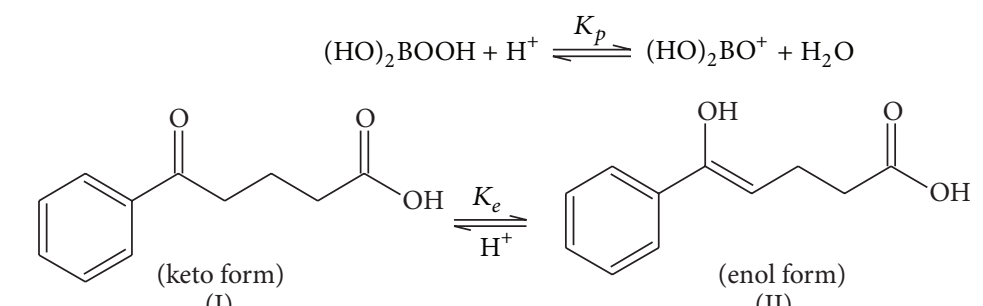

(I)

(II)

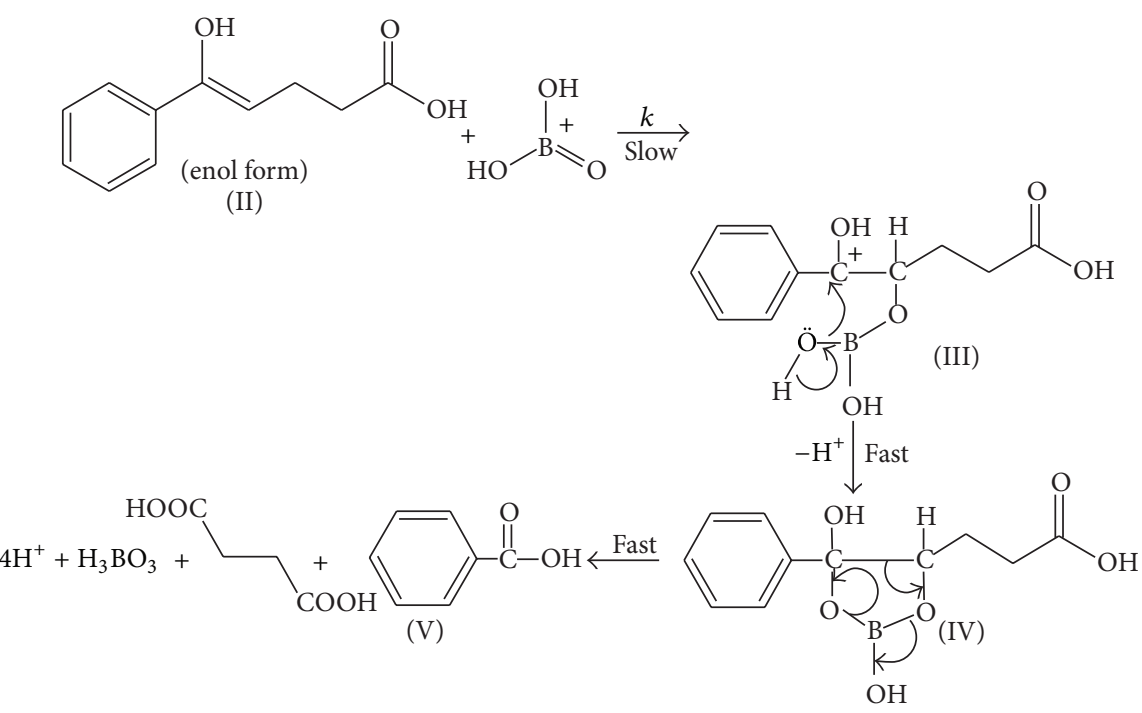

Scheme 1: Formations of benzoic acid and succinic acid were the final products of oxidation.

The obtained rate law could explain the second order in $\left[\mathrm{H}^{+}\right]$ and first order both in [perborate] and [5-oxoacid].

\section{Conclusions}

The above study shows that the $\mathrm{H}_{2} \mathrm{BO}_{3}{ }^{+}$reacts with the enol form of 5-oxoacid in the rate determining step, giving the cyclic boronate ester. Decomposition of the boronate ester results in the cleavage of the carbon-carbon bond, yielding carboxylic acids. This experimental protocol suggests that this reaction could find utility as a regioselective route for the synthesis of carboxylic acids, specially succinic and benzoic acids.

\section{Conflict of Interests}

The authors declare that there is no conflict of interests regarding the publication of this paper.

\section{References}

[1] T. M. Connor and R. E. Richards, "Nuclear resonance spectra of some peroxy-salts," Journal of the Chemical Society, pp. 289-293, 1958.

[2] J. O. Edwards and V. F. Ross, "The Structural chemistry of the borates," in The Chemistry of Boron and Its Compounds, E. L. Muetterties, Ed., p. 192, John Wiley \& Sons, New York, NY, USA, 1967.
[3] F. A. Cotton and G. Wilkinson, Advanced Inorganic Chemistry, Wiley Interscience, New York, NY, USA, 1988.

[4] Y. Ogata and H. Shimizu, "Oxidation of organic compounds with perborates or $\mathrm{H}_{2} \mathrm{O}_{2}$-boric acids," Bulletin of the Chemical Society of Japan, vol. 52, no. 2, pp. 635-636, 1979.

[5] A. McKillop and W. R. Sanderson, "Sodium perborate and sodium percarbonate: cheap, safe and versatile oxidising agents for organic synthesis," Tetrahedron, vol. 51, no. 22, pp. 61456166, 1995.

[6] A. McKillop and W. R. Sanderson, "Sodium perborate and sodium percarbonate: further applications in organic synthesis," Journal of the Chemical Society, Perkin Transactions, vol. 1, no. 4, pp. 471-476, 2000.

[7] J. Muzart, "Sodium perborate and sodium percarbonate in organic synthesis," Synthesis, no. 11, pp. 1325-1347, 1995.

[8] C. Karunakaran and P. N. Palanisamy, "Kinetic evidence for (N,N-dimethylaniline)-oxodiperoxomolybdenum(VI) or tungsten(VI) as oxidizing species in molybdenum(VI) or tungsten(VI) catalyzed hydrogen peroxide (Perborate) oxidation of $\mathrm{N}, \mathrm{N}$-dimethylaniline," Synthesis and Reactivity in Inorganic and Metal-Organic Chemistry, vol. 28, pp. 1115-1125, 1998.

[9] C. Karunakaran and B. Muthukumaran, "Zirconium(IV) catalysis in perborate oxidation of iodide," Reaction Kinetics and Catalysis Letters, vol. 60, pp. 387-394, 1997.

[10] C. Karunakaran and B. Muthukumaran, "Molybdenum(VI) catalysis of perborate or hydrogen peroxide oxidation of iodide ion," Transition Metal Chemistry, vol. 20, no. 5, pp. 460-462, 1995. 
[11] C. Karunakaran and P. Manimekalai, "Kinetics and mechanism of perborate oxidation of organic sulphides," Tetrahedron, vol. 47, no. 41, pp. 8733-8738, 1991.

[12] C. Karunakaran and R. Kamalam, "On the mechanism of the perborate oxidation of organic sulfides in glacial acetic acid," European Journal of Organic Chemistry, no. 19, pp. 3261-3263, 2000.

[13] C. Karunakaran, V. Ramachandran, and P. N. Palanisamy, "Linear free energy relationship in complex reaction: tungsten(VI) catalyzed perborate oxidation of S-Phenylmercaptoacetic acids," International Journal of Chemical Kinetics, vol. 31, pp. 675-681, 1999.

[14] C. Karunakaran and R. Kamalam, "Mechanism and reactivity in perborate oxidation of anilines in acetic acid," Journal of the Chemical Society. Perkin Transactions, vol. 2, no. 12, pp. 20112018, 2002.

[15] D. Kungumathilagam and K. Karunakaran, "Kinetics and mechanism of meso-tetraphenylporphyriniron(III) chloride (TPP) catalysed oxidation of indole by sodium perborate," Polish Journal of Chemical Technology, vol. 15, no. 2, pp. 107-111, 2013.

[16] N. P. Marigangaiah and K. K. Banerji, "Kinetics \& mechanism of oxidation of acetone, butanone, pentan-2-one, 3-methylbutan2-one, hexan-2-one \& 4-methylpentan-2-one by acid permanganate," Indian Journal of Chemistry A, vol. 14, pp. 660-662, 1976.

[17] A. Meenakshi and M. Santhappa, "Oxidation studies involving Tl(III)," Indian Journal of Chemistry, vol. 11, pp. 393-394, 1973.

[18] N. A. M. Farook, "Kinetics of oxidation of 4-oxoacids by Nchlorosaccharin in aqueous acetic acid medium," Journal of Solution Chemistry, vol. 36, no. 3, pp. 345-356, 2007.

[19] N. A. Mohamed Farook and G. A. Seyed Dameem, "Kinetics of oxidation of 3-benzoylpropionic acid by $\mathrm{N}$-chlorobenzamide in aqueous acetic acid medium," E-Journal of Chemistry, vol. 8, no. 2, pp. 561-564, 2011.

[20] D. F. Gnana Rani, F. J. M. Pushparaj, I. Alphonse, and K. S. Rangappa, "Kinetics and mechanism of oxidation of 4-oxoacids by hexacyanoferrate(III) catalysed by Os(VIII)," Indian Journal of Chemistry B, vol. 41, no. 10, pp. 2153-2159, 2002.

[21] G. Sikkandar, "Kinetics of oxidative decarboxylation of $\beta$-Benzoylpropionic acid by Manganese (III) acetate," Asian Journal of Chemistry, vol. 12, no. 4, pp. 1037-1040, 2000.

[22] B. Kenneth, K. Wiberg, and R. Stewart, "Solvents having high dielectric constants. II. Solutions of alkali halides in Nmethylacetamide from 30 to $60^{\circ}$," Journal of the American Chemical Society, vol. 77, pp. 1986-1989, 1955.

[23] A. I. Vogel, Text Book of Quantitative Chemical Analysis, ELBS, Longmans, New York, NY, USA, 5th edition, 1958.

[24] F. C. Tompkins, "Kinetics of the oxidation of organic compounds by potassium permanganate. Part VI. Benzaldehyde," Transactions of the Faraday Society, vol. 39, pp. 280-287, 1943.

[25] F. R. Duke, "The disproportionation of manganate ion. Managanese dioxide as heterogeneous catalyst," The Journal of Physical Chemistry, vol. 56, pp. 882-884, 1952.

[26] M. G. Alder and J. E. Leffler, "The role of the solvent in radical decomposition reactions: phenylazotriphenylmethane," Journal of the American Chemical Society, vol. 76, no. 5, pp. 1425-1427, 1954.

[27] F. Feigl and V. Anger, Spot Tests in Organic Analysis, Amsterdam, The Netherlands, Elsevier, 1975.
[28] F. A. Long and M. A. Paul, "Application of the HO acidity function to kinetics and mechanisms of acid catalysis," Chemical Reviews, vol. 57, pp. 955-1010, 1957.

[29] C. S. Reddy and T. Vijaya Kumar, "Aquachlororuthenium(III) complex catalysis in the oxidation of malonic and methylmalonic acids by bromate in perchloric acid medium. Study of induction period and evaluation of individual kinetic parameters," Transition Metal Chemistry, vol. 32, pp. 246-256, 2007.

[30] E. S. Amis, Solvent Effects on Reaction Rates and Mechanisms, Academic Press, New York, NY, USA, 1967.

[31] J. E. Leffler and E. Grunwald, Rates and Equilibrium of Organic Reactions, John Wiley \& Sons, New York, NY, USA, 1963.

[32] R. Schmid and V. N. Sapunov, Non-Formal Kinetics, Verlag, Chemie, Weinheim, Germany, 1982.

[33] Adams and R. M. Boron, Metallo-Boron Compounds and Boranes, Interscience, New York, NY, USA, 1964.

[34] G. Sikkandar, K. A. B. Ahamed, and S. Kannan, "Kinetics of oxidation of 4-oxoacids by permanganate in buffer media," Indian Journal of Chemistry A, vol. 38, no. 2, pp. 183-186, 1999.

[35] S. Venkatakrishnan and M. Santappa, "Oxidation of acetone and methyl ethyl ketone by ceric ions in aqueous solution," Zeitschrift für Physikalische Chemie, vol. 16, pp. 73-84, 1958.

[36] J. S. Littler, "The mechanisms of oxidation of cyclohexanone under acid conditions. Part II. One-electron oxidants," Journal of the Chemical Society, pp. 832-837, 1962.

[37] D. G. Hoare and W. A. Waters, "Oxidations of organic compounds by cobaltic salts. Part II. The oxidation of diethyl ketone," Journal of the Chemical Society, pp. 971-975, 1962.

[38] A. J. Green, T. J. Kemp, S. S. Littler, and W. A. Waters, “The mechanism of oxidation of cyclohexanone under acid conditions. Part III. Corrected enolization rates and kinetic isotope effects," Journal of the Chemical Society, pp. 2722-2726, 1974.

[39] G. Sarala, P. J. P. Rao, B. Sethuram, and T. N. Rao, "Kinetics and mechanism of uncatalyzed and Os(VIII)-catalyzed oxidation of acetophenones by diperiodatoargentate(III)," Indian Journal of Chemistry A, vol. 26, pp. 475-479, 1987.

[40] A. Y. Drumond and W. A. Waters, "Stages in oxidations of organic compounds by potassium permanganate. Part VI. Oxidations of ketones and of pyruvic acid," Journal of the Chemical Society, pp. 497-504, 1955.

[41] P. S. R. Murthy and S. N. Pati, "Oxidation of aliphatic, arylaliphatic and cyclic-ketones by thallium triacetate," Indian Journal of Chemistry A, vol. 17, pp. 97-101, 1979.

[42] M. A. A. Siddiqui, C. S. Kumar, U. Chandraiah, and S. Kandlikar, "Kinetics of oxidation of acetophenones by diperiodatonickelate(IV) in the presence and absence of Os(VIII)," Indian Journal of Chemistry A, vol. 30, pp. 849-854, 1991.

[43] W. S. Nathan and H. B. Waston, "Constitutional factors controlling prototropic changes in carbonyl compounds. Part III. The prototropy of nuclear-substituted," Journal of the Chemical Society, pp. 217-220, 1933. 

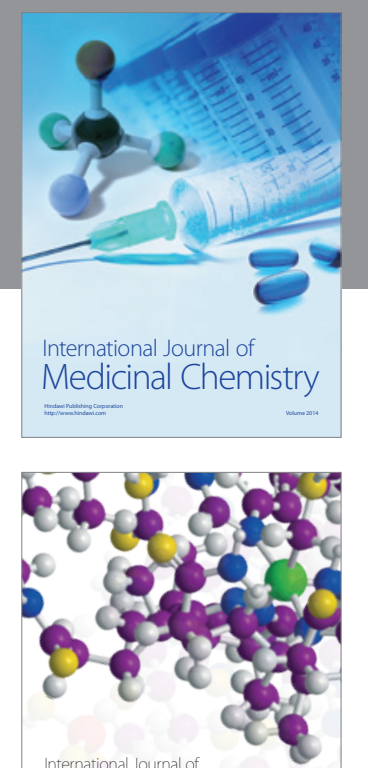

\section{Carbohydrate} Chemistry

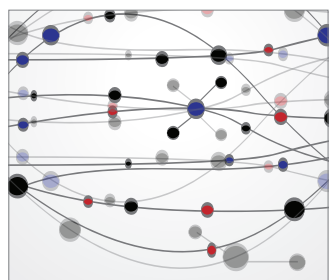

The Scientific World Journal
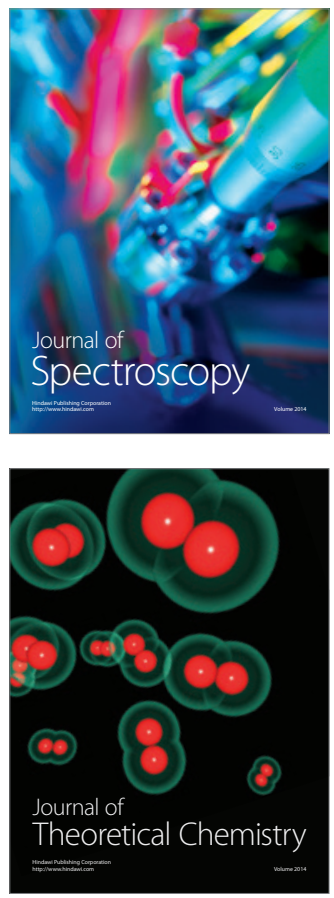
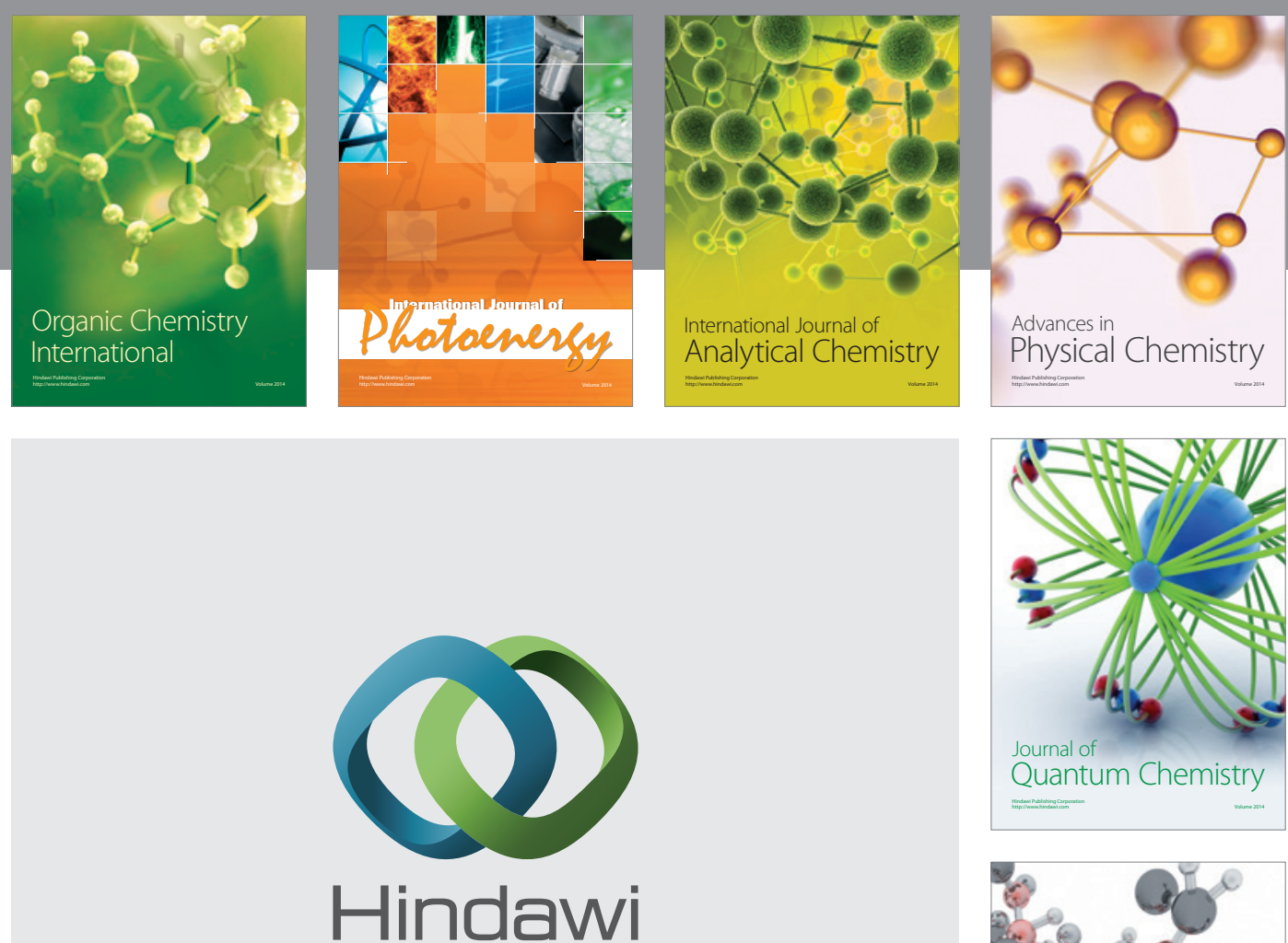

Submit your manuscripts at

http://www.hindawi.com

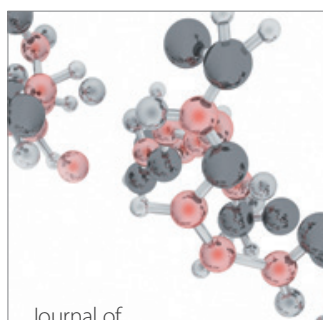

Analytical Methods

in Chemistry

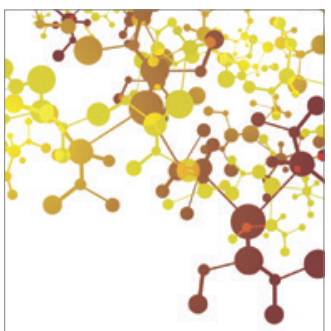

Journal of

Applied Chemistry

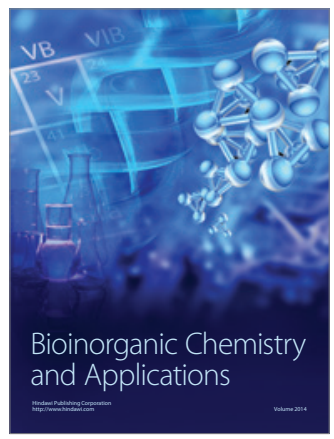

Inorganic Chemistry
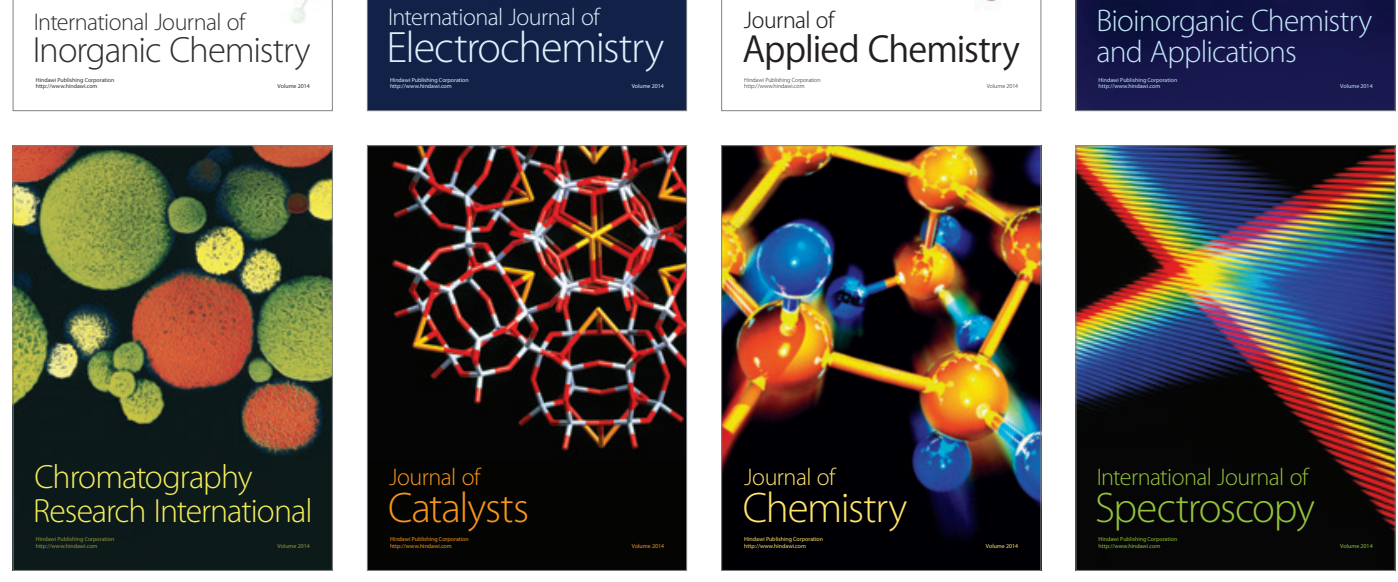